\title{
POSIBLES ESTADOS DEPRESIVOS EN LA VIDA MONACAL: UNA APROXIMACIÓN PSICOLÓGICA
}

\author{
FRANCISCO MÁRQUEZ \\ Experto y Especialista Universitario en Psicopatología y Salud (UNED)
}

(Aceptado en febrero de 2001)

\begin{abstract}
En este trabajo se realiza una primera aproximación al posible significado patológico de algunos estados emocionales descritos desde los primeros tiempos de cristianismo, por diversas personas que han abrazado la profesión religiosa, y más concretamente la vida monástica. La similitud de los síntomas que caracterizan aquellas condiciones psicológicas con los que presentan determinados cuadros depresivos justifica un examen de la, en ocasiones, probable identificación entre ambos.
\end{abstract}

Palabras clave: Vida monástica, acedia, aridez, desolación, depresión.

Possible depressive disorders in the monastic life: a psychological approach

This work examines the possible pathological meaning of some emotional states described from the earliest times of the Christianity by different people who have adopted the religious profession and more specifically the monastic life. The resemblance of symptoms that typify those psychological conditions and the ones seen in some depressive disorders warrant an exam for a possible identification of both.

Key words: Monastic life, heartbum, aridity, desolation, depression.

\section{INTRODUCCIÓN}

La literatura espiritual cristiana de todas las épocas contiene innumerables testimonios de personas que, habiendo abrazado la profesión religiosa, y especialmente la vida monástica, manifiestan haber atravesado, al menos alguna vez, períodos de abatimiento, tristeza, desolación, etc., a los que generalmente atribuyen un origen sobrenatural, considerándolos una prueba de origen divino y naturaleza obligada en el camino de la perfección.

Sin prejuicio de que dichos estados emocionales tengan, en determinadas ocasiones, una causa distinta, lo cierto es que, al acercarse a su descripción sorprende, cuando menos, el parecido con un cuadro depresivo. También se ha de precisar que las referencias a estos estados de ánimo difieren entre sí en cuanto

Correspondencia: Francisco Márquez, c/ Olmillo 4 y 6, bajo B, 14008 Córdoba, Teléfono 957412241. a la estructura de los mismos, a veces en aspectos sustanciales, por lo que han de examinarse separadamente, como afecciones psíquicas diferentes.

Realizaremos este breve análisis, fundamentalmente, en el marco del modelo clínico de la depresión elaborado por el profesor Francisco Alonso-Fernández, dentro de cuyas dimensiones (humor depresivo, anergia, discomunicación y ritmopatía) se situarán los posibles síntomas presentes en las circunstancias examinadas (Alonso-Fernández, 1988, 1994).

El primeramente citado de estos extraños estados psicológicos es la acedia, mencionada ya en la literatura moral y ascética desde la época patrística. El término "acedia" (o acidia), del griego $\alpha \kappa \eta \delta \imath \alpha$, sin cuidado, tiene también, ya desde los autores clásicos paganos (Empédocles, Hipócrates, Cicerón), el significado de tristeza y tedio. Su identificación con la tristeza procede, en occidente, de san Gre- 
gorio Magno, continuando con el mismo sentido en otros maestros del espíritu. En el siglo VI, Juan Casiano introduce la acepción oriental de la acedia en la espiritualidad occidental definiéndola como

Una ansiedad o un tedio del corazón que convierte al hombre en sedentario e inhábil, para cualquier obra (...), le vuelve ocioso y vacío para cualquier ejercicio espiritual (...); además, sus deberes le cansan, sus trabajos le aburren (Honings, 1975).

Es significativo que san Juan Clímaco hable de la acedia como "la eterna compañera del monje solitario, que no le dejará hasta la muerte y cada día le hostigará", lo que ha llevado a Honings (1975) a calificarla como «una especie de enfermedad profesional del claustro". ¿Quiere esto decir que se trata de algún tipo de estado psíquico cronificado? Es difícil creerlo. San Juan de la Cruz se refiere a la acedia como «vicio» que puede afectar al principiante en su recién comenzado itinerario hacia la perfección causándole "tedio en las cosas que son más espirituales (...)" (Noche, lib. I, cap. VII, 2). Para este santo, la causa de la acedia se halla en que los religiosos principiantes, en algún determinado momento, no hallan complacencia en sus principales actividades, como la oración. Sin embargo, este sentimiento, para san Juan Clímaco se halla instalado de por vida en el psiquismo del monje.

¿Qué es realmente la acedia? Trueman Dicken (1963) habla de su «efecto depresivo" y se refiere a ella como "enfermedad que hoy día escapa a menudo al diagnóstico». Partiendo del hecho de que parece tratarse de estados emocionales distintos aunados bajo la misma denominación a través de la historia, se nos presentan más dignas de atención las descripciones de Juan Clímaco y san Casiano, por cuanto se refieren a un esta- do psicológico perdurable, reiterativo $\mathrm{y}$, aparentemente, más grave que el simple "vicio de principiantes" de san Juan de la Cruz.

Junto a la acedia, la aridez y la desolación son otros estados psicológicos de los que también hablan los religiosos. Para Bortone (1975), la aridez, dificultad más o menos acusada en el ejercicio de la oración, puede tener como causas de naturaleza psíquica la neurastenia y psicastenia. La desolación, además, «comporta un estado general de depresión, de amargura, de desánimo de ningún modo compatible con el fervor espiritual.»

Consideramos de mayor interés, en relación con la depresión, otros testimonios de personas con más o menos larga experiencia de vida contemplativa, $y$, por lo general, de gran fervor y profunda convicción religiosa. Entre la diversidad de relatos que dan cuenta de estos estados de ánimo, hemos seleccionado uno, citado por el P. Arintero y especialmente representativo, por cuanto que en él se describe un grupo importante de lo que pudieran interpretarse como síntomas depresivos:

Parece que lo he perdido todo, todo, sin que me quede nada más que una sensación de nada y de muerte que me hiela... Parece que he caído en un pozo hondísimo y tenebroso donde no veo ni entiendo ni sé nada... Parece que he perdido a Dios, la fe, la esperanza, el amor, como si nunca lo hubiera sentido. Me siento como una imbécil que ni sufrir ni desear sabe... No puedo obrar ni por temor ni esperanza, porque siento como si después de todo no hubiera más que la nada (Arintero, 1956).

¿Podría el tipo de vida religioso, con sus peculiares características en cuanto a actividad (regularidad, monotonía, repetición) y relaciones de las personas que conviven (situación social) favorecer la aparición de un proceso depresivo? Dos de los subtipos de la denominada por 
Alonso-Fernández «depresión situacional» nos parecen aquí especialmente merecedores de atención, siendo la situación social (relación interactiva entre la persona y su entorno social), como una de las vías hacia la depresión, el denominador común de ambos (Alonso-Fernández, 1994).

En este sentido se dan, efectivamente, una serie de condiciones sociales propiciatorias de un tipo de síndrome depresivo denominado depresión por aislamiento, caracterizado por un «bloqueo de la comunicación» (Alonso-Fernández, 1994). La posible amistad o confidencialidad entre personas que conviven en un claustro tienen connotaciones especiales. Las relaciones personales se dan siempre en un trasfondo religioso, que impregna la totalidad de la vida de estos sujetos. Las vivencias y sentimientos más íntimos, no tendrán, muchas veces, entre estas personas cauce adecuado para manifestarse. E incluso si son analizados desde una óptica religiosa, la persona puede tratar de reprimir, de alguna forma, un determinado sentir al atribuirle un posible contenido pecaminoso. Esta falta de comunicación de su intimidad puede llevar al religioso a una experiencia profunda de soledad.

La incorporación a la vida monástica conlleva una importante modificación de la actividad normal de la persona. Los hábitos han de adaptarse a la nueva situación, y prácticamente todas las funciones básicas para la vida, entre ellas las pautas de sueño, aspecto tan importante en la depresión, sufren alguna variación. Esta alteración súbita en la forma de vida se halla en el origen de la depresión por crisis (Alonso-Fernández, 1994). Tanto la depresión por aislamiento como la depresión por crisis podrían tener alguna relación con la acedia, tal como la describen Juan Clímaco y Juan Casiano.

Mayor importancia parece revestir, sin embargo, el estado anímico citado por
Arintero. En él se evidencian, junto a la tristeza y abatimiento habituales en la depresión (Vázquez y Sanz, 1995), la amargura, pesadumbre y desesperanza sobre las que se enfatizan las preocupaciones morales, autoacusaciones y profundo sentimiento de culpabilidad que Alonso-Fernández sitúa en la vertiente psíquica del humor depresivo, primera de las dimensiones que constituyen su modelo clínico (Alonso-Fernández, 1988). Las ideas de indignidad y reproche de sí mismo (Coderch, 1991, Kaplan y Sadock, 1987) suelen aparecer en estas manifestaciones, atribuyéndose al hecho de que es Dios mismo quien causa al místico este sentir mostrándole la realidad de su alma, manchada por el pecado. Es también muy probable que un estado psíquico como el apuntado vaya acompañado de una intensa ansiedad (Coderch, 1991).

No cabe duda de que, junto a estos síntomas se da también el descenso de impulsos hacia la actividad normal y habitual de la persona (anergia) como ponen de relieve muchos otros testimonios (Alonso-Fernández, 1988). Sin embargo, no parece darse, en estos sujetos, una voluntad de abandonar la actividad que, ante todo, constituiría para ellos un grave incumplimiento de sus deberes para con Dios y que, por otra parte, tampoco es probable que fuese consentido por los superiores. Muy interesante por su posible significado depresivo nos parece también la expresa alusión, en este testimonio, a la incapacidad de tener sentimientos de ningún tipo (Alonso-Fernández, 1988, Vázquez y Sanz, 1995).

Por último, el sentido de prueba divina atribuido por estos sujetos a su estado anímico puede hacerles descartar (o ni siquiera contemplar) la idea del suicidio, ya que no aparece mención alguna a la misma en este tipo de declaraciones siendo considerado aquél, además, un gran acto de pecado. 
Además de las esbozadas en este trabajo, la mística ofrece otras interesantes perspectivas de investigación psicológica. Son frecuentes, por ejemplo, las descripciones referentes a la «iluminación» que parecen recibir, a veces, los místicos sobre determinados aspectos de su personalidad, como si atravesasen una especie de proceso psicoanalítico, o las repetidas alusiones a la "nada» interpretable, en principio, como sentimiento de profundo y terrible vacío interior.

\section{REFERENCIAS BIBLIOGRÁFICAS}

Alonso-Fernández, F. (1988). La depresión y su diagnóstico. Nuevo modelo clínico. Barcelona: Labor.

Alonso-Fernández, F. (1994). Vencer la depresión. Madrid: Temas de Hoy.

Arintero, J.G. (1956). Cuestiones místicas. Madrid: Biblioteca de Autores Cristianos.
Baden, H.J. (1981). Das Erlebnis Gottes. Friburgo: Herder.

Bortone, E. (1975). Aridez. En Ancilli, E. (dir.), Dizionario enciclopedico di sipiritualità, vol. I. Roma: Studium.

Coderch, J. (1991). Psiquiatría dinámica. Barcelona: Herder.

Honings, B. (1975): Acedia. En Ancilli, E. (dir.), Dizionario enciclopedico di sipiritualità, vol. I. Roma: Studium.

Kaplan, H.I., y Sadock, B.J. (1987): Modern Synopsis of Comprehensive Textbook of Psychiatry/IV. Baltimore: Williams \& Wilkins.

San Juan de la Cruz (1982). Obras completas. Madrid: Biblioteca de Autores Cristianos.

Trueman Dicken, E.W. (1963). The crucible of love. Londres: Darton, Logman and Todd.

Vázquez, C., y Sanz, J. (1995). Trastornos del estado de ánimo: Aspectos clínicos. En A. Belloch, B. Sandín y F. Ramos (Eds.), Manual de Psicopatología (Vol. 2). Madrid: McGraw-Hill. 